\title{
An Integrated ISFET pH Microsensor on a CMOS Standard Process
}

\author{
Francisco López-Huerta ${ }^{1 *}$, Rosa María Woo-Garcia ${ }^{2}$, Miguel Lara-Castro ${ }^{1}$, \\ Johan Jair Estrada-López ${ }^{3}$, Agustín Leobardo Herrera-May ${ }^{1}$ \\ ${ }^{1}$ Research Center for Micro and Nanotechnology, University of Veracruz, Veracruz, Mexico \\ ${ }^{2}$ Faculty of Electronics Sciences, Meritorious Autonomous University of Puebla, Puebla, Mexico \\ ${ }^{3}$ Faculty of Mathematics, Autonomous University of Yucatán, Mérida, Mexico \\ Email: *frlopez@uv.mx
}

Received June 7, 2013; revised July 7, 2013; accepted July 15, 2013

Copyright (C) 2013 Francisco López-Huerta et al. This is an open access article distributed under the Creative Commons Attribution License, which permits unrestricted use, distribution, and reproduction in any medium, provided the original work is properly cited.

\begin{abstract}
We present the design and integration of a nine-pH microsensor array on a single silicon substrate with its own signal readout circuit, integrated in a $0.6-\mu \mathrm{m}$ commercial standard complementary metal oxide semiconductor (CMOS) process. An ion sensitive field effect transistor (ISFET) has been used as $\mathrm{pH}$ microsensor and an instrumentation amplifier as the read-out circuit. The ISFET structure is conformed by the channel length and ratio of MOS transistor, gate extended and the selective membrane, for which silicon nitride $\left(\mathrm{Si}_{3} \mathrm{~N}_{4}\right)$ is employed as an ion selective element. The complete design includes shielding around the $\mathrm{pH}$ microsensor and the readout circuit to avoid leakage of current to the substrate. The readout circuit is composed by three operational amplifiers and resistances that form the instrumentation amplifier, with a $\pm 2.5 \mathrm{~V}$ bias has a $50 \mathrm{~dB}$ gain, power supply rejection ratio (PSSR) of $120 \mathrm{~dB}$ and common mode rejection ratio (CMRR) of $127 \mathrm{~dB}$. The complete system is integrated in a $1.12 \mathrm{~mm}^{2}$ silicon area; it presents a $59 \mathrm{mV} / \mathrm{pH}$ linearity, within a concentration range of 2 to $12 \mathrm{of} \mathrm{pH}$ level, making it a good alternative for biological or medical applications.
\end{abstract}

Keywords: CMOS; Instrumentation Amplifier; ISFET; pH

\section{Introduction}

The ion sensitive field effect transistor (ISFET) has been used as $\mathrm{pH}$ sensor during the last years; also, they can detect chemical and biological phenomena or even can be used for biosensing [1-8]. Actually, the research, design, development and application of ISFET-based sensors have displaced to the ion sensitive electrodes (ISE), $\mathrm{pH}$ indicator strips and optical sensors $[9,10]$ due to their great advantages such as mass-production low cost, light weight, small size, fast response, low output impedance, high speed signal, distributed sensing, multiplexing possibilities and temperature compensation; also, it allows that not only the readout circuits but also their control system can be integrated on the same integrated circuit (IC) in standard consumer CMOS processes [11-14], offering new tendencies for solid state sensors.

ISFET based electrochemical $\mathrm{pH}$ sensors have found applications in many fields such as environmental monitoring, agriculture, medicine, biological sensing and me-

*Corresponding author. dical diagnosis [13-18]. Variations that exist in the ISFET selectivity depend on the selective membrane employed, the most used materials are: $\mathrm{Al}_{2} \mathrm{O}_{3}, \mathrm{Si}_{3} \mathrm{~N}_{4}, \mathrm{SiO}_{2}$, $\mathrm{TaO}_{5}, \mathrm{ZrO}_{2}, \mathrm{SnO}_{2} / \mathrm{Al}$; also, other kind of materials like polymers, metallic oxides and organic/inorganic materials [19-27] are used for this purpose. These materials are widely used due to its high selectivity with the hydrogen ions. ISFET structure is different to the conventional FET structure due to an exterior exposed window that is left inside the sensor structure where the sensitive material will be deposited to form the selective membrane of the hydrogen ions or others [28,29].

Particularly, the integration of sensors and electronics on the same substrate potentiate the benefits of the devices, improving functionalities like signal amplification, calibration and better signal to noise ratio. All these advantages drive to call the attention for the studying and producing of ISFETs to apply them in many knowledge areas. The basic requirements that a sensor must accomplish are 1) the superficial dielectric located in the ISFET gate region must have a sensibility as great as pos- 
sible to detect the $\mathrm{pH}$ levels of the analyzed solution with rapidness, efficiency and reliability; 2) the selected dielectric material must present an amount of drift current and hysteresis as minimum as possible during measurements, which is important if the ISFETs are used to measure $\mathrm{pH}$ levels for long periods of time. This last condition makes them very useful in biomedical field $[18,27,30]$. During the last years, the design and research of ISFETs and readout circuits have been developed in different ways, some authors do the research about the sensor and the others use the standard consumer CMOS technology, where the $\mathrm{pH}$ sensors and readout circuits are on the same substrate, including a reference electrode that is connected externally [31,32].

Considering the disadvantages previously presented, we can say that it is a necessity to do research related with microelectromechanical systems (MEMS) to improve the $\mathrm{pH}$ microsensors' characteristics. In this work, we propose the integration of $9 \mathrm{pH}$ microsensors, implemented with ISFET's, all of them have their own readout circuit associated. In addition, the reference electrode is integrated in the same silice substrate, using a $0.6 \mu \mathrm{m}$ standard consumer CMOS process, wherewith very high level of reproducibility and dimension control of the fabricated devices will be obtained. Electrical properties of $\mathrm{Si}_{3} \mathrm{~N}_{4}$ will be used to form the selective membrane for hydrogen ions.

This paper is organized as follows: in Section 2, we describe both ISFET $\mathrm{pH}$ microsensor and readout circuit formed by an instrumentation amplifier and analog amplifier. The results and experimental data are described in Section 3. Finally, we present our conclusions and proposed future research in Section 4.

\section{Design of the ISFET pH Microsensor}

\subsection{ISFET Devices}

We design the ISFET $\mathrm{pH}$ microsensor using a standard $0.6 \mu \mathrm{m}$ triple metal, double poly layer CMOS ON Semiconductor process [33]. The ISFET's structure is conformed by a transistor geometric ratio, extended gate and the selective membrane (Figure 1), for which silicon

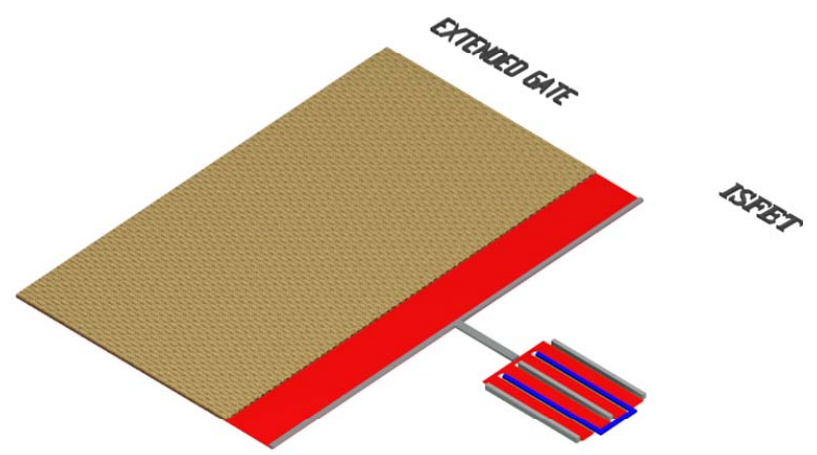

Figure 1. Schematic of the ISFET pH microsensor. nitride $\left(\mathrm{Si}_{3} \mathrm{~N}_{4}\right)$ is employed as an ion selective element. The complete design includes shielding around the ISFET $\mathrm{pH}$ microsensor and the readout circuit to avoid leakage of current to the substrate.

The conventional MOSFET structure is different from ISFET since the sensor structure is left exposed the extension gate on which the sensitive material deposited for forming the selective membrane of hydrogen ions. The operation of the ISFET $\mathrm{pH}$ microsensor is similar to that the conventional metal oxide semiconductor field effect transistor (MOSFET) The Equation (1) for the ISFET in saturation as a function of the $\mathrm{pH}[20]$ :

$$
I_{D}=\frac{\mu_{n} C_{e f f}}{2} \frac{W}{L}\left(V_{G}-V_{T}^{*}\right)^{2}\left(1+\lambda V_{D S}\right)
$$

where $\mu_{n}$ is the mobility of the electrons in the channel, $C_{\text {eff }}$ the capacitance effective per unit area Equation (2), $W$ and $L$ the width and length of the channel, respectively, $V_{G}$ the gate voltage, $V_{T}^{*}$ the threshold voltage of the ISFET Equation (3), $V_{D S}$ the drain to source voltage, $\lambda$ the channel modulation parameter.

$$
C_{\text {eff }}=\frac{C_{o x} C_{M}}{C_{o x}+C_{M}}
$$

where $C_{o x}$ the capacitance per unit area of the gate insulator and $C_{M}$ is the capacitance of the selective membrane.

$$
V_{T}^{*}=V_{T}-\frac{R T}{n F} \ln \left(a_{i}\right)+V_{R e f}
$$

$V_{T}$ the threshold voltage, $R$ the universal gas constant, $T$ the absolute temperature, $n$ the numbers of electrons perm mole, $F$ the Faraday constant, $a_{i}$ the activity of the ions and $V_{R e f}$ is the voltage of reference electrode.

\subsection{CMOS Integrated Readout Circuit for pH Measurement}

The instrumentation amplifier readout circuit for the ISFET $\mathrm{pH}$ microsensor was designed to have a high input impedance, high common mode rejection ratio (CMRR) and power supply rejection ratio (PSRR). Figure 2 shows the readout circuit used for the $\mathrm{pH}$ measurement. The resistors R1-R4 were all $10 \mathrm{k} \Omega$ and $\mathrm{R}$ was $20 \mathrm{k} \Omega$. The ISFET as sensible element to detect the $\mathrm{pH}$ changes can detect certain molecules in chemical solutions. The chemical reaction changes the charge stores on the gate and shifts the threshold voltage of the transistor. The current variations due to different $\mathrm{pH}$ levels cause the ISFET $\mathrm{pH}$ microsensor, behaves as a variable resistance (depended a chemical solutions) connected between the source (node A) and the drain (node B), obtaining different gains for the readout circuit. The emulated resistance can be written by Equation (4): 


$$
R=\frac{1}{\partial I_{D} / \partial V_{D S}}=\frac{L}{\mu_{n} C_{e f f} W\left(V_{G}-V_{T}^{*}\right)}
$$

In order to integrate both the ISFET $\mathrm{pH}$ microsensor and the readout circuit, we used the geometric pattern editor of L-Edit of Tanner ${ }^{\circledR}$ [34]. The readout circuit is also formed by three analog amplifiers and each one of them with a voltage gain of 1000, and Figure 3 shows the schematic. The analog amplifier has a first stage integrated by differential-pair transistors M1-M2 and a polarization through transistors M5 and M6. The biasing of the circuit is made by means of a current mirror formed by the resistor $R 1$ and transistors M3-M4. In order to improve the stability of this circuit, the compensation is implemented by the transistors M7-M10 as well as a capacitor $C_{c}$ [35]. The final stage consists of transistors M11 and M12 that form a buffer. Table 1 shows the channel length and width (aspect ratios) of all MOS transistors obtained for the proposed design in this work.

Our design for the measurement of pH ISFETs has 9 which present different aspect ratio to vary the sensitivity and dynamic range of detection of microsensors, Table 2 shows the dimensions. Each $\mathrm{pH}$ microsensor consists of

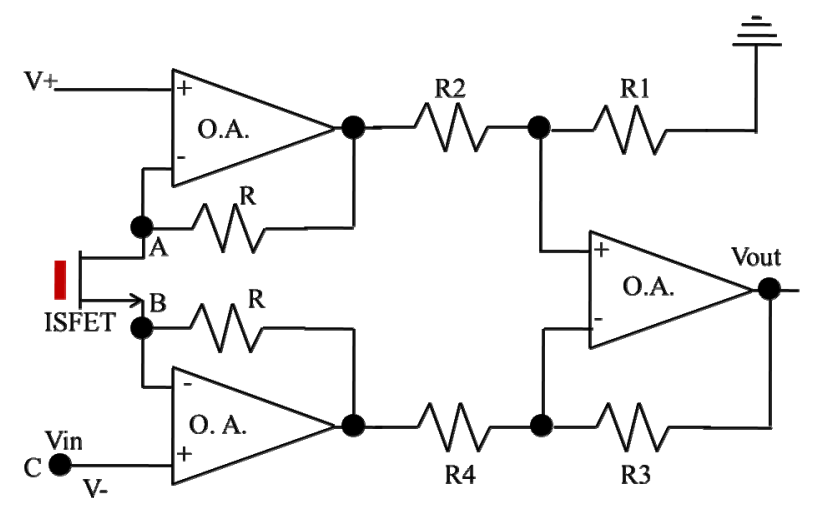

Figure 2. Block schematic of our system implementation.

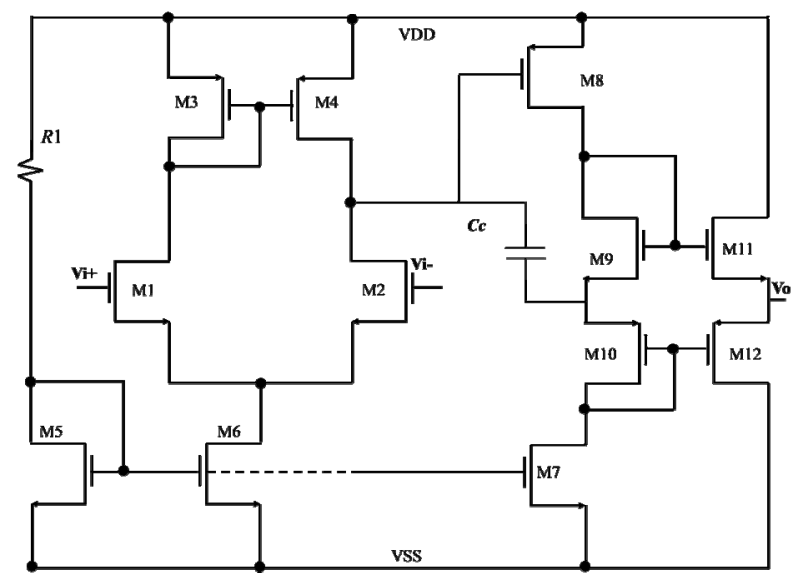

Figure 3. Schematic of the analog amplifier used in our design. the extended gate, the ISFET structure and the readout circuit formed by the instrumentation amplifier (Figure 4). The union between the extended gate and ISFET was made with a distance equivalent to all sensors, and each element is aligned there by facilitating the etching on metal or depositing the material to form the membrane sensitive to hydrogen ions. Figure 5 shows a cross section of the layers used in the CMOS process and the ion sensitive membrane sensitive. In this figure, metal layers are ML1, ML2, ML3 and the contacts between are via1 and via2.

\section{Results and Discussions}

The electrical results of the ISFET pH microsensor simulations were obtained from the analysis conducted with a

Table 1. Aspect ratio of the transistors for the proposed design.

\begin{tabular}{cc}
\hline Devices & $W / L(\mu \mathrm{m})$ \\
\hline M1-M2 & $7.2 / 1.2$ \\
M3-M4 & $16.8 / 1.2$ \\
M5-M7 & $4.8 / 1.2$ \\
M8 & $33.6 / 1.2$ \\
M9 & $24 / 1.2$ \\
M10 & $74 / 1.2$ \\
M11 & $360 / 1.2$ \\
M12 & $1197 / 1.2$ \\
\hline
\end{tabular}

Table 2. Aspect ratio of the ISFET pH microsensor array.

\begin{tabular}{ccc}
\hline$W / L(20)$ & $W / L(25)$ & $W / L(30)$ \\
\hline $24 / 1.2$ & $30 / 1.2$ & $36 / 1.2$ \\
$60 / 3$ & $60 / 2.4$ & $54 / 1.8$ \\
$96 / 8$ & $90 / 3.6$ & $108 / 3.6$ \\
\hline
\end{tabular}

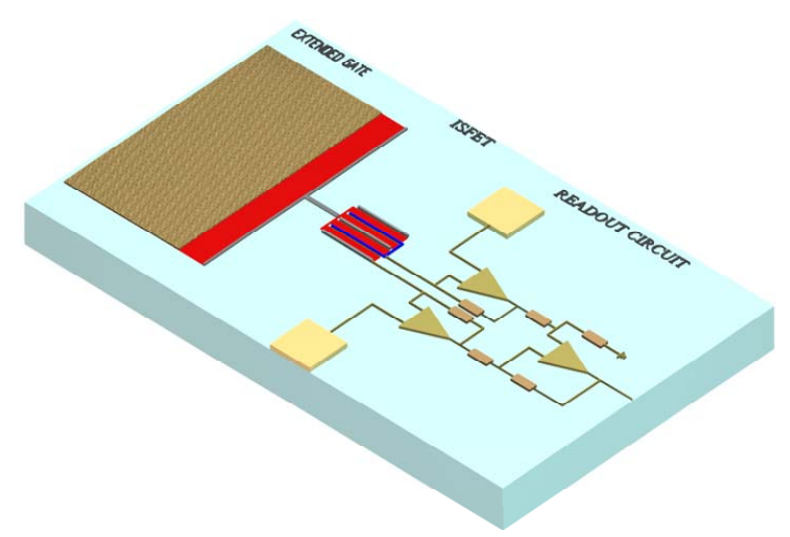

Figure 4. Diagram of an ISFET pH microsensor. 
circuit simulator. A sinusoidal excitation signal of 200 $\mathrm{mVpp}$ at $1 \mathrm{kHz}$ is supplied to the readout circuit and its output signal is amplified more than 20 times ( $26 \mathrm{~dB}$ ), as shown in Figure 6.

The common mode rejection ratio (CMRR) simulated in the readout circuit was $127 \mathrm{~dB}$ at $20 \mathrm{kHz}$, as shown in Figure 7.

The Figure 8 shows the dynamic range for three ISFET pH microsensor, 20, 25 and 30, the sensibility as function of the aspect ratio of the ISFET and the sensible material $\mathrm{Si}_{3} \mathrm{~N}_{4}$. From this discussion it can be said that using all microsensors a $\mathrm{pH}$ range from 2 to 12 could be covered. The second observed situation is the variation on the microsensor sensitivity for low $\mathrm{pH}$ values, the slope of the curves changes, in the $\mathrm{pH}$ range of $1-3$. Such slope increase when the aspect ratio is 30 , as shown in Figure 9.

The $\mathrm{pH}$ microsensors' response and dynamic range

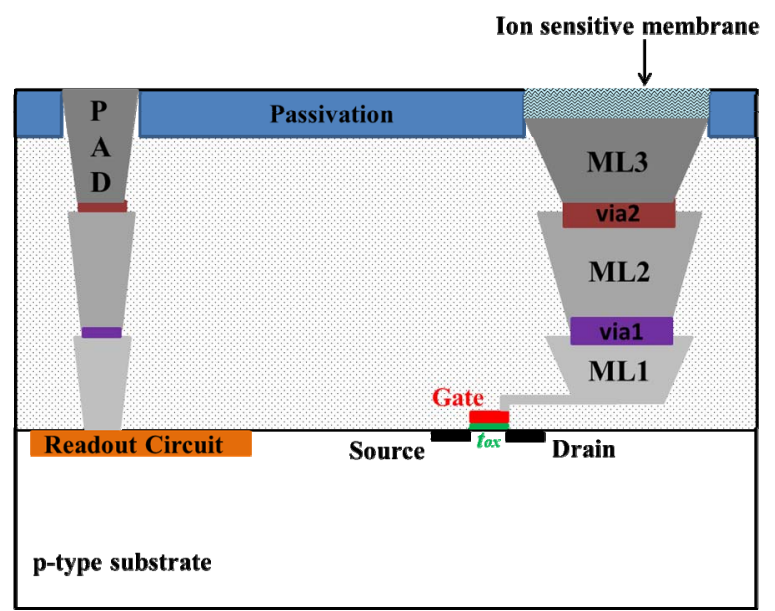

Figure 5. Cross section of the layers employed for the ISFET pH microsensor.

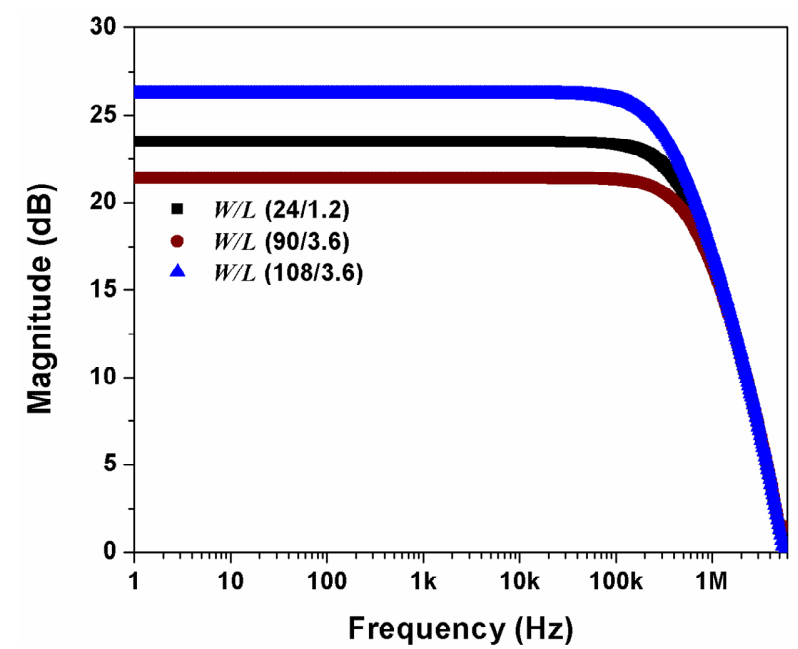

Figure 6. Frequency response of the readout circuit of the pH microsensor.

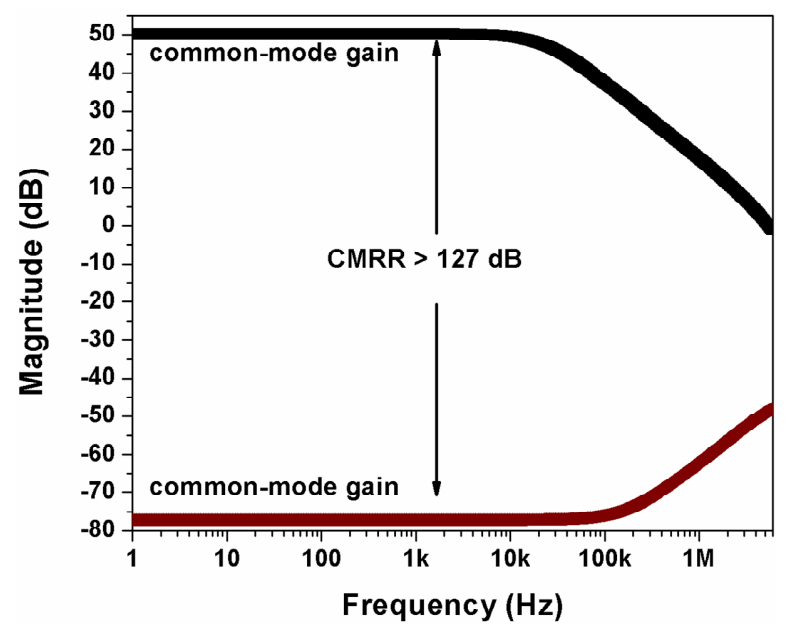

Figure 7. Common mode rejection ratio in the readout electrical circuit of the $\mathrm{pH}$ microsensor.

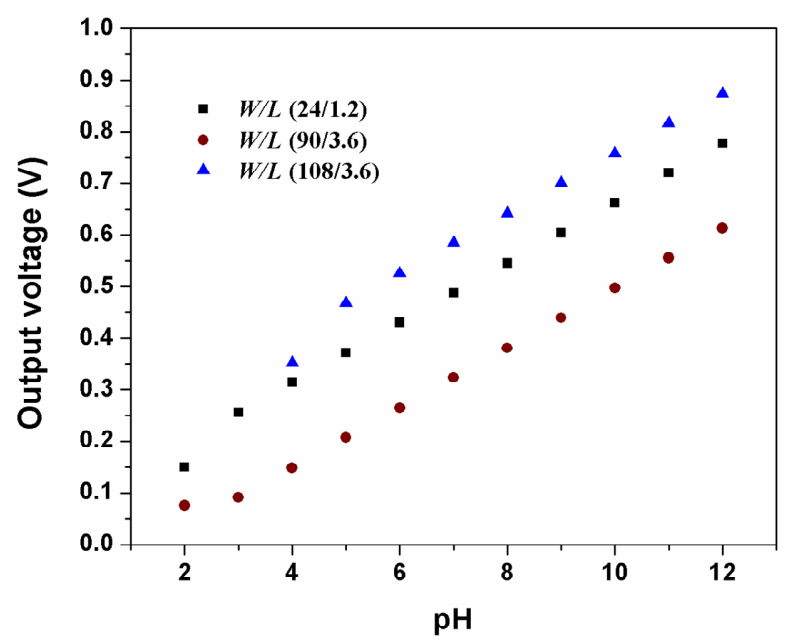

Figure 8. Response curves of the $\mathrm{pH}$ microsensor.

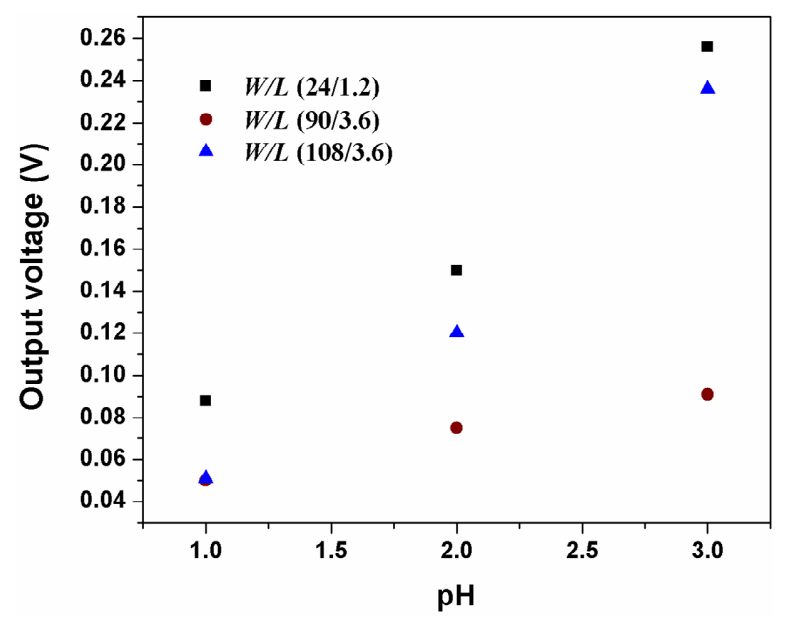

Figure 9. Microsensor responses for different $\mathrm{pH}$ values.

were obtained simulating the performance of each of them for different $\mathrm{pH}$ levels that vary from acidic to alkaline 
(2 - 12) through the electrical simulator.

The preliminary test of the electrical performance characteristics will be obtained of the ISFET $\mathrm{pH}$ microsensor, using an arbitrary waveform generator, a digital oscilloscope and two power supplies. The ISFET's pH microsensos works with a \pm 2.5 volts DC and was packaged with a DIP-24 (twenty-four dual in-line package). The voltage applied to reference electrode is set to 2 volts, a sinusoidal excitation signal of $200 \mathrm{mV}$ peak to peak at $1 \mathrm{kHz}$ is supplied to the amplifier and its output signal is amplified as a function of the $\mathrm{pH}$ level. In order to measure the cutoff frequency of the amplifier, a frequency sweep for its input signal from $0.5 \mathrm{~Hz}$ to 1.5 $\mathrm{MHz}$ will be applied. The $\mathrm{pH}$ level is controlled using $\mathrm{KOH}$ and $\mathrm{HNO}_{3}$ to increase and decrease it, respectively [10]. Figure 10 shows a schematic with the main components of a signal conditioning system that could be used for $\mathrm{pH}$ microsensor. Figure 11 shows the microphotograph of the chip, which was fabricated by MOSIS [36] and the distribution for ISFET, extended gate and readout circuit.

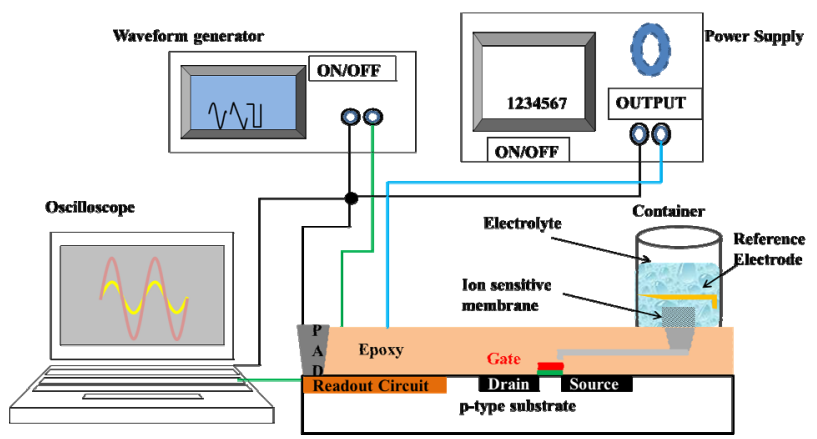

Figure 10. Schematic of the signal condition system for the ISFET pH microsensor.

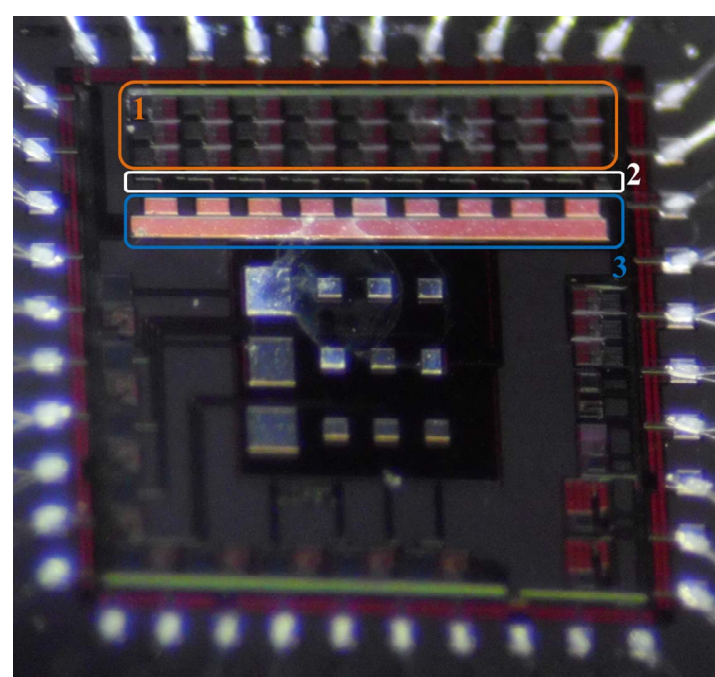

Figure 11. Microphotograph of the ISFET pH microsensor. Selective parts are numbered. 1 . Readout circuit; 2 . ISFET; 3. Extended Gate.

\section{Conclusion}

The design of an ISFET pH microsensor array based on CMOS process using ON Semiconductor technology was presented. The microsensor array includes the following elements: the ISFET (with different area), extended gate $(100 \times 100 \mu \mathrm{m})$ and readout circuit $(213 \times 272.4 \mu \mathrm{m})$. This array was designed to detect different $\mathrm{pH}$ level values with a simple signal conditions system. It presented a linear response for $\mathrm{pH}$ levels between $2 \mathrm{pH}$ and $12 \mathrm{pH}$, and resolution around the $60 \mathrm{mV} / \mathrm{pH}$. Future work will include the electrical characterization of the $\mathrm{pH}$ microsensor array under different $\mathrm{pH}$ levels and the deposition of some materials on surface extended gate.

\section{Acknowledgements}

Authors wish to thank the facilities provided by MOSIS Research Program and CONACYT through grant 48757.

\section{REFERENCES}

[1] P. Bergveld, "Development of an Ion Sensitive Solid State Device for Neurophysiological Measurements," IEEE Transactions on Biomedical Engineering, Vol. 17, No. 1, 1970, pp. 70-71.

[2] C. Soo, S. K. Kim and M. Kim, "Ion Sensitive Field Effect Transistor for Biological Sensing,” Sensors, Vol. 9, No. 9. 2009, pp. 7111-7131, doi:10.3390/s90907111

[3] P. Bergveld, "The Operation of an ISFET as an Electron Device,” Sensors and Actuators, Vol. 1, 1981, pp. 17-29. doi:10.1016/0250-6874(81)80004-2

[4] P. Bergveld, "The Future of Biosensors," Sensors and Actuators A: Physical, Vol. 56, No. 1-2, 1996, pp. 65-73. doi:10.1016/0924-4247(96)01275-7

[5] K. M. Chang, C. T. Chang and K. M. Chan, "Development of an Ion Sensitive Field Effect Transistor Based Urea Biosensor with Solid State Reference Systems," Sensors, Vol. 10, No. 6, 2010, pp. 6115-6127. doi:10.3390/s100606115

[6] G. Shalev, A. Cohen, A. Doron, A. Machauf, M. Horesh, U. Virobnik, D. Ullien and L. Ilan, "Standard CMOS Fabrication of a Sensitive Fully Depleted Electrolyte-Insulator-Semiconductor Field Effect Transistor for Biosensor Applications,” Sensors, Vol. 9, No. 6, 2009, pp. 4366-4379. doi:10.3390/s90604366

[7] M. J. Schöning and A. Poghossian, "Recent Advances in Biologically Sensitive Field-Effect Transistors (BioFETs)," Analyst, Vol. 127, No. 6, 2002, pp. 1137-1151. doi:10.1039/b204444g

[8] W. Olthuis, "Chemical and Physical FET-Based Sensors or Variations on an Equation," Sensors and Actuators B: Chemical, Vol. 105, No. 1, 2005, pp. 96-103. doi:10.1016/j.snb.2004.02.040

[9] G. P. Chen, R. M. Xia, J. Gong and W. D. Shou, "Study on pH Effect in Process of an Entero-Gastric Fiber-Optic Sensor Design,” Sensors, Vol. 2, No. 11, 2002, pp. 447 454. doi:10.3390/s21100447 
[10] G. Beltrán-Pérez, F. López-Huerta, S. Muñoz-Aguirre, J. Castillo-Mixcoatl, R. Palomino-Merino, R. Lozada-Morales and O. Portillo-Moreno, "Fabrication and Characterization of an Optical Fiber pH Sensor Using Sol-Gel Deposited $\mathrm{TiO}_{2}$ Film Doped with Organic Dyes," Sensors and Actuators B: Chemical, Vol. 120, No. 6, 2006, pp. 74-78. doi:10.1016/j.snb.2006.01.048

[11] C.-L. Dai, P.-W. Lu, C.-C. Wu and C. Chang, "Fabrication of Wireless Micro Pressure Sensor Using the CMOS Process,” Sensors, Vol. 9, No. 11, 2009, pp. 8748-8760. doi:10.3390/s91108748

[12] E. Lauwers, J. Suls, W. Gumbrecht, D. Maes, G. Gielen and W. Sansen, "A CMOS Multiparameter Biochemical Microsensor with Temperature Control and Signal Interfacing," IEEE Journal of Solid-State Circuits, Vol. 36, No. 12, 2001, pp. 2030-2038. doi:10.1109/4.972154

[13] A. Morgenshtein, L. Sudakov-Boreysha, U. Dinnar, C. G. Jakobson and Y. Nemirovsky, "CMOS Readout Circuitry for ISFET Microsystems,” Sensors and Actuators B: Chemical, Vol. 97, No. 1, 2004, pp. 122-131. doi:10.1016/j.snb.2003.08.007

[14] V. P. Chodavarapu, A. H. Titus and A. N. Cartwright, "Differential Read out Architecture for CMOS ISFET Microsystems," Electronics Letters, Vol. 41, No. 12, 2005, pp. 698-699. doi:10.1049/el:20051044

[15] M. Futagawa, T. Iwasaki, H. Murata, M. Ishida and K. Sawada, "A Miniature Integrated Multimodal Sensor for Measuring $\mathrm{pH}, \mathrm{EC}$ and Temperature for Precision Agriculture,” Sensors, Vol. 12, No. 6, 2012, pp. 8338-8354. doi:10.3390/s120608338

[16] C. Jimenez-Jorquera, J. Orozco and A. Baldi, "ISFET Based Microsensors for Environmental Monitoring," Sensors, Vol. 10, No. 1, 2012, pp. 61-83. doi:10.3390/s100100061

[17] S. Martinoia, N. Rosso, M. Grattarola, L. Lorenzelli, B. Margesin and M. Zen, "Development of ISFET ArrayBased Microsystems for Bioelectrochemical Measurements of Cell Populations," Biosensors and Bioelectronics, Vol. 16, No. 9-12, 2001, pp. 1043-1050. doi:10.1016/S0956-5663(01)00202-0

[18] V. P. Chodavarapu, A. H. Titus and A. N. Cartwright, "CMOS ISFET Microsystem for Biomedical Applications," Proceedings of IEEE Sensors Conference, Irvine, 30 October-3 November 2005, pp. 109-112.

[19] Y. I. Huang, R. S. Huang and L. L. His, “A New Structured ISFET with Integrated Ti/PdAg/AgCl Electrode and Micromachined Back-Side P+ Contacts," Journal of the Chinese Institute of Engineers, Vol. 25, No. 3, 2002, pp. 327-334. doi:10.1080/0253389.2002.9670707

[20] C. Lung, Y. Chuan, T. Ping, H. Kwei, W. Yaw and S. Kan, "A Novel $\mathrm{SnO}_{2} / \mathrm{Al}$ Discrete Gate ISFET pH Sensor with CMOS Standard Process," Sensors and Actuators B: Chemical, Vol. 75, No. 1-2, 2001, pp. 36-42. doi:10.1016/S0925-4005(00)00739-5

[21] K.-M. Chang, C.-T. Chang, K.-Y. Chao and C.-H. Lin, "A Novel pH-Dependent Drift Improvement Method for Zirconium Dioxide Gated pH-Ion Sensitive Field Effect Transistors," Sensors, Vol. 10, No. 5, 2010, pp. 46434654. doi:10.3390/s100504643
[22] G. Scarpa, A.-L. Idzko, A. Yadav and S. Thalhammer, "Organic ISFET Based on Poly (3-hexylthiophene)," Sensors, Vol. 10, No. 3, 2010, pp. 2262-2273. doi:10.3390/s100302262

[23] A. Loi, I. Manunza and A. Bonfiglio, "Flexible, Organic, Ion-Sensitive Field-Effect Transistor," Applied Physics Letters, Vol. 86, No. 10, 2005, pp. 103512-1-103512-3. doi:10.1063/1.1873051

[24] S. S. Jan, Y. C. Chen, J. C. Chou, P. J. Jan and C. C. Cheng, "Preparation and Properties of Hydrogen IonSensitive Field Effect Transistors with Sol-Gel-Derived Mg-Modified Lead Titanate Gate,” Journal of NonCrystalline Solids, Vol. 332, No. 1, 2003, pp. 11-19. doi:10.1016/j.jnoncrysol.2003.08.054

[25] I. Poels, R. B. M. Schasfoort, S. Picioreanu, J. Frank, G. W. K. van Demen, A. van den Berg and L. Nagels, "An ISFET Based Anion Sensor for Potentiometric Detection of Organic Acids in Liquid Chromatography,” Sensors and Actuators B: Chemical, Vol. 67, No. 3, 2000, pp. 249-299.doi:10.1016/S0925-4005(00)00531-1

[26] F. Yan, P. Estrela, Y. Mo, P. Migliorato and H. Maeda, "Polycrystalline Silicon ISFETs on Glass Substrate," Sensors, Vol. 5, No. 4, 2005, pp. 293-301. doi:10.3390/s5040293

[27] C. Moldovan, R. Iosub, M. Modreanu, D. Ulieru, B. Firtat and M. Ion, "ISFET Microsensors $\mathrm{HfO}_{2}$ Based for Biomedical Applications,” International Semiconductor Conference, Sinaia, 27-29 September 2006, pp. 185-188,

[28] S. P. Lee, J. G. Lee and S. Chowdhury, "CMOS Humidity Sensor System Using Carbon Nitride Film as Sensing Materials,” Sensors, Vol. 8, No. 4, 2008, pp. 2662-2672. doi:10.3390/s8042662

[29] C. G. Ahn, A. Kim, C. W. Park, C. S. Ah, J. H. Yang, T. Y. Kim, M. Jang and G. Y. Sung, "Modified Ion Sensitive Field Effect Transistor Sensors Having an Extended Gate on a Thick Dielectric,” Applied Physics Letters, Vol. 96, No. 20, 2010, pp. 203702-1-203702-3. doi:10.1063/1.3431296

[30] K. Nakazato, “An Integrated ISFET Sensor Array,” Sensors, Vol. 9, No. 11, 2009, pp. 8831-8851. doi:10.3390/s91108831

[31] K. Cao, “A Chemical Sensor Design Using a Standard CMOS Process,” Master's Thesis, University of Manitoba, Winnipeg, 2007.

[32] R. M. Woo-García, F. López-Huerta, J. J. Estrada-López and B. S. Soto, "S. Electrochemical pH Sensor Integrated with Standard CMOS Process,” Ingeniería, Vol. 15, No. 2, 2011, pp. 69-79.

[33] “On Semiconductor ${ }^{\circledR}, ” 2012$. http://www.onsemi.com/

[34] “Electronic Design,” 2012. http://www.tannereda.com/

[35] F. López-Huerta, J. J. Estrada-López, M. Linares-Aranda, C. Zúñiga-Islas and B. S. Soto, "Study and Comparison of CMOS Layouts for Applications in Analog Circuits," Journal of Scientific and Industrial Research, Vol. 71, No. 4, 2012, pp. 257-261.

[36] “Integrated Circuit Foundry,” 2012. http://www.mosis.com/ 